\title{
MOSQUITO LARVICIDAL EFFICACY OF THE ACETONE LEAF EXTRACT OF SOLANUM TRILOBATUM AGAINST CULEX QUINQUEFASCIATUS AND AEDES AEGYPTI
}

\author{
LALITHA A, THANGAPANDIYAN S*
}

Department of Zoology, PSG College of Arts and Science, Coimbatore, Tamil Nadu, India. Email: stp.nano@gmail.com Received: 21 May 2018, Revised and Accepted: 01 August 2018

\begin{abstract}
Objective: The main objective of our study is to control the vector-borne disease. It is one among the major disease burden in developing countries. There are lots of researches carried out using the various plant extracts against larvicidal activities of the Culex quinquefasciatus and Aedes aegypti. The present investigation was aimed to investigate the phytochemical analysis and mosquito larvicidal activities of Solanum trilobatum in acetone extract against the second instar larvae of $C$. quinquefasciatus and $A$. aegypti.
\end{abstract}

Methods: The leaf extract of $S$. trilobatum was subjected to phytochemical analysis and Gas Chromatography-Mass Spectrometry analysis. The mortality rates of the second instar larvae were recorded after $24,48,72$, and $96 \mathrm{~h}$ of exposure. The lethal concentration (LC) ${ }_{50}$ and $\mathrm{LC}_{90}$ were determined followed by probit analysis.

Results: $\mathrm{The}_{50}$ values for $C$. quinquefasciatus were found to be $265.69 \mathrm{ppm}, 227.59 \mathrm{ppm}, 212.42$ ppm, and 189.47 ppm at various time intervals, and the $\mathrm{LC}_{90}$ values were $558.27 \mathrm{ppm}, 504.92 \mathrm{ppm}, 479.09 \mathrm{ppm}$, and $444.28 \mathrm{ppm}$. Similarly, LC ${ }_{50}$ values for A. aegypti were noticed at 301.09 ppm, $256.01 \mathrm{ppm}, 209.75 \mathrm{ppm}$, and $167.44 \mathrm{ppm}$ and the $\mathrm{LC}_{90}$ values were $582.34 \mathrm{ppm}, 477.52 \mathrm{ppm}, 419.40 \mathrm{ppm}$, and $371.84 \mathrm{ppm}$ for the time interval of $24 \mathrm{~h}, 48 \mathrm{~h}, 72 \mathrm{~h}$, and $96 \mathrm{~h}$.

Conclusion: The result of the current work revealed that the leaf extract of the $S$. trilobatum has the potential to be acted as an alternative for the controlling of the mosquitoes.

Keywords: Gas Chromatography-Mass Spectrometry, Phytochemical analysis, Probit analysis, Mortality rate.

(C) 2018 The Authors. Published by Innovare Academic Sciences Pvt Ltd. This is an open access article under the CC BY license (http://creativecommons. org/licenses/by/4. 0/) DOI: http://dx.doi.org/10.22159/ajpcr.2018.v11i12.27432

\section{INTRODUCTION}

Mosquito-borne disease is a major health problem in worldwide for both human and veterinary sectors. Mosquitoes are a serious threat to the public and also health transmitting several dangerous diseases in tropics [1]. Diseases transmitted by mosquitoes include malaria, dengue hemorrhagic fever, Japanese encephalitis, yellow fever, and filariasis [2]. One of the prime concerns of malaria treatment is increase in the alarming rate of resistance to different antimalarial drugs [3]. There are about 3500 species of mosquitoes have been reported. Among the 13 genera of the family Culicidae, besides, Anopheles and Culex individuals of genus Aedes are considered as dangerous because they cause public health threat worldwide [4].

In the past years, the plant kingdom has been of great interest potential source of insecticidal products. Many number of plant species are playing an important role in insecticidal products. Plants synthesize a variety of secondary metabolites which play a key role in defense against mosquitoes [5]. Phytochemicals are mostly secondary metabolites extracted from various plant species have been tested for their larvicidal activity against mosquitoes [6]. Phytochemicals obtained from plants are usually harmless, easily biodegradable and comparatively safer to human and environment. Hence, the present study revealed the interest in the research on these compounds, considering them as an ecologically safe alternative for synthetic insecticides [7].

Solanum trilobatum is an important medicinal plant in Ayurveda and Siddha systems, commonly available in Southern India and has been used in herbal medicine to treat various diseases such as respiratory problems, bronchial asthma, and tuberculosis [8,9]. The leaves and stem of $S$. trilobatum are reported to possess antimitotic, antiinflammatory, and antiulcerogenic properties [10]. The leaves contain rich amount of calcium, iron, phosphorus, carbohydrates, proteins, fat, crude extracts, and minerals [11]. Leaf extract of $S$. trilobatum possesses potent larvicidal against Culex quinquefasciatus, oviposition deterrent, and skin repellent activity against Anopheles stephensi [12]. Various chemical constituents are reported to be isolated from Solanum species, which includes alkaloids, phenolics, flavonoids, sterols, saponins, and their glycosides [13]. Alkaloids such as soladunalinidine and tomatidine were isolated from leaf and stem of Solanum species. Therefore, the present investigation was carried out to determine the mosquito larvicidal activity of $S$. trilobatum leaf against two mosquito vectors C. quinquefasciatus and Aedes aegypti.

\section{METHODS}

\section{Plant collection and extraction}

Healthy, disease free, mature leaves of $S$. trilobatum were collected from the region of Annur, Coimbatore District, Tamil Nadu. The collected plant material was identified and authenticated in Tamil Nadu Agricultural University (TNAU), Tamil Nadu. Leaves of S. trilobatum washed thoroughly with running tap water. The leaves were again washed with sterile distilled water to remove the dirt before drying process. Then, the leaves were dried in shade room temperature for a week to remove moisture content and powdered using mixer grinder. Finally, powdered sample was stored at room temperature for further studies. $2.5 \mathrm{~g}$ of powdered leaf sample was taken in air-tight bottles. To this, $50 \mathrm{ml}$ of acetone was added. After $48 \mathrm{~h}$, the contents were stirred well thoroughly and filtered through Whatman No. 1 filter paper. The filtrate was collected and stored in sterile bottles at $4^{\circ} \mathrm{C}$ until further use.

\section{Phytochemical analysis of $S$. trilobatum}

Freshly prepared leaf extracts of $S$. trilobatum were subjected to standard phytochemical analysis according to Trease and Evans [14] to find out the presence of various phytochemical constituents. 
Gas Chromatography-Mass Spectrum (GC-MS) analysis

GC-MS analysis is a common confirmation test to separate all the compounds in a sample and provides a representative spectral output. The sample is injected into the injection port of the GC device. The GC instruments vaporize the sample and then separate and analyze the various compounds ideally produce a specific spectral peak that may be recorded on a paper chart or electronically. The retention time can help to differentiate between some compounds. The size of the peaks is proportional to the quantity of the corresponding substances in the specimen analyzed. An aliquot of $2 \mu \mathrm{l}$ of sample was injected with temperature at $280^{\circ} \mathrm{C}$. GC oven temperature started at $70^{\circ} \mathrm{C}$ and holding for $8 \mathrm{~min}$, and it was raised to $220^{\circ} \mathrm{C}$ holding for $7 \mathrm{~min}$ at the rate of $10^{\circ} \mathrm{C} / \mathrm{min}$. Iron source temperature was maintained at $300^{\circ} \mathrm{C}$. The detector was operated scan mode form with interval of $0.50 \mathrm{~s}$.

\section{Preparation of stock solution}

Dried and powdered aerial parts (1 kg) were macerated sequentially with $3 \mathrm{~L}$ of acetone for $96 \mathrm{~h}$ and filtered. The crude plant extracts were evaporated to dryness in a room temperature.

\section{Test organisms}

The II instar larvae of $C$. quinquefasciatus and $A$. aegypti obtained from National Institute for Communicable Disease (NICD), Mettupalayam, Coimbatore, Tamil Nadu, India. The larvae were kept in enameled trays containing tap water. The larvae were maintained at $25-29^{\circ} \mathrm{C}$ and $75-85 \%$ relative humidity under 14:10 light and dark cycles.

\section{Larvicidal bioassay}

The larvicidal bioassay was carried out according to standard the WHO protocol with minor modifications. From the stock solution, different concentrations of $100,200,300,400$, and $500 \mathrm{ppm}$ were prepared. 25 healthy second instar larvae were introduced into beaker containing $200 \mathrm{ml}$ of water with each test concentration. Larval mortality was observed at $24 \mathrm{~h}, 48 \mathrm{~h}, 72 \mathrm{~h}$, and $96 \mathrm{~h}$. A total of three trials were performed [15].

Percent mortality $=\frac{\text { Number of deadlarvae }}{\text { Number of larvaintoduced }} \times 100$

\section{Statistical analysis}

SPSS 12 version package was used for the determination of lethal concentration $\mathrm{LC}_{50}$ and $\mathrm{LC}_{90}$ (LC causing 50 and $90 \%$ mortality). The experiment data of larval mortality and effect of concentration were subjected to analysis of variance (ANOVA) followed by probit analysis to determine the difference in larval mortality between concentrations.

\section{RESULTS AND DISCUSSION}

\section{Phytochemical screening}

The preliminary phytochemical analysis of the $S$. trilobatum leaf extract of acetone solvent revealed the presence of alkaloids, tannins, steroids, glycosides, and phenols (Table 1). Balakrishnan et al. [16] observed that S. trilobatum leaf extracts contained various phytochemical compounds such as alkaloids, flavonoids, carbohydrates, glycosides, saponins, tannins, terpenoids, proteins, and anthraquinone. The present results of phytochemical compounds are coincident with other researchers [17-19].

\section{GC-MS analysis}

Plant possesses immense medicinal properties. The aim of the present work was to identify the phytochemicals present in acetone extracts of the leaves of $S$. trilobatum by qualitative photochemical testing and to identify the compounds present in the acetone extract of the leaves by GCMS analysis (Fig. 1). The GC-MS spectrum revealed that the acetone leaf extract of $S$. trilobatum contained the major phytochemical compounds such as cyclodecanol (12.42\%), 2-tetradecycloxirane $(6.07 \%)$, betasitosterol (10.25\%), 1H-imidazole, 4,5-dimethyl-imidazole (4.65\%), 1-octadecyne $(4.30 \%)$, and phenol $(4.05 \%)$. The other compounds also identified are diisoamylene (2.90\%), chloro-5-iodo-benzoic acid pyridine-3-yl methylene-hydrazide (1.70\%), 4-(2-oxo-bicyclo (3.1.0)
Table 1: Qualitative phytochemical analysis of Solanum trilobatum leaf extracts

\begin{tabular}{lll}
\hline Compounds & Test adopted & Acetone extract \\
\hline Alkaloids & Mayer's test & + \\
Terpenoids & Salkowski test & - \\
Flavonoids & Sodium hydroxide test & - \\
Tannins & Lead acetate test & + \\
Steroids & Chloroform test & + \\
Anthraquinones & Free anthraquinones test & - \\
Saponins & Foam test & - \\
Resins & Sodium hydroxide test & - \\
Glycosides & Keller-Killiani's test & + \\
Phenols & Ferric chloride test & + \\
\hline
\end{tabular}

+: Present, -: Absent

hex-6-yl (1.57\%), permethrin-1,3-phenoxybenzyl (1.36), 1H-pyrazole5-carboxamide (2.38\%), 2-cyclohexen-1-ol (1.38\%), benzene,2-(tertbutyldimethylsilyl) oxy (2.63\%), hydrochlorothiazide N-butylbronate $(1.99 \%)$, silicic acid diethyl bis(trimethylsilyl)ester $(2.83 \%)$, and isopropyl tris (3.48\%) (Table 2). Its presence in the plant suggests that it to be of medicinal value because tannins have shown potential antiviral and antiparasitic effects [20]. Krishnaiah and Prashanth [21] reported that the similar compound detected was 3,7,11,15-tetramethyl-2hexadecen-1-ol in the present result.

\section{Larvicidal activity}

Larvicidal activity of acetone extract of $S$. trilobatum leaves at various concentrations was tested against filarial and dengue vectors such as $C$. quinquefasciatus and A. aegypti. Acetone extract of $S$. trilobatum leaves exhibited potential larvicidal activity at varying concentrations, whereas no larval death was observed in controls. The mortality rate obtained was $25.33 \%$ (24 h) and $37.33 \%$ (96 h) at a concentration of $100 \mathrm{ppm}$, whereas the maximum mortality rate was obtained at $500 \mathrm{ppm}$ for $24 \mathrm{~h}(86.7 \%)$ and $96 \mathrm{~h}(97.33 \%)$. It clearly depicted that the larvicidal effect of acetone leaf extract of $S$. trilobatum was a dose dependent as well as duration of exposure. Similarly, larvicidal effect of acetone extract of $S$. trilobatum on A. aegypti exhibited minimum larval death rate at concentration of $100 \mathrm{ppm}$ in $24 \mathrm{~h} \mathrm{(17.33 \% )}$ and $96 \mathrm{~h}$ (38.67\%). The maximum mortality $81.33 \%$ and $100 \%$ was observed at a concentration of $500 \mathrm{ppm}$ at $24 \mathrm{~h}$ and $96 \mathrm{~h}$, respectively. The mortality rate was recorded maximum at $96 \mathrm{~h}$ compared to 24,48 , and $72 \mathrm{~h}$ for both C. quinquefasciatus and A. aegypti.

The $\mathrm{LC}_{50}$ values for $C$. quinquefasciatus were found to be $265.69 \mathrm{ppm}$, $227.59 \mathrm{ppm}, 212.42 \mathrm{ppm}$, and $189.47 \mathrm{ppm}$ for the time intervals of $24 \mathrm{~h}, 48 \mathrm{~h}, 72 \mathrm{~h}$, and $96 \mathrm{~h}$, respectively. Similarly, LC $_{50}$ values for A. aegypti were noticed at $301.09 \mathrm{ppm}, 256.01 \mathrm{ppm}, 209.75 \mathrm{ppm}$, and 167.44 ppm at time intervals of $24 \mathrm{~h}, 48 \mathrm{~h}, 72 \mathrm{~h}$, and $96 \mathrm{~h}$, respectively. $\mathrm{LC}_{90}$ values also calculated for both $C$. quinquefasciatus and $A$. aegypti. The $\mathrm{LC}_{90}$ value for $C$. quinquefasciatus was $558.27 \mathrm{ppm}, 504.92 \mathrm{ppm}$, $479.09 \mathrm{ppm}$, and $444.28 \mathrm{ppm}$ for the time interval of $24 \mathrm{~h}, 48 \mathrm{~h}, 72 \mathrm{~h}$, and $96 \mathrm{~h}$, respectively. The $\mathrm{LC}_{90}$ values of $A$. aegypti were $582.34 \mathrm{ppm}$, $477.52 \mathrm{ppm}, 419.40 \mathrm{ppm}$, and $371.84 \mathrm{ppm}$ for the time interval of $24 \mathrm{~h}$, 48 h, 72 h, and 96 h, respectively (Table 3 ).

Regression analysis revealed that the mortality rate (Y) was positively correlated with the concentration (X). Two-way ANOVA analysis demonstrated that the larvicidal effect exhibited by various concentrations of acetone leaf extract of $S$. trilobatum on C. quinquefasciatus and A. aegypti was statistically significant $(\mathrm{p}<0.05)$ at 48 and $96 \mathrm{~h}$.

Rajkumar and Jebanesan [12] reported that the acetone leaf extract of $S$. trilobatum acts as oviposition deterrents. This indicates that C. quinquefasciatus and A. aegypti mosquitoes were acutely sensitive to phytochemical stimuli and responded to the odor of the acetone leaf extract produce maximum effective repellency against oviposition. Premalatha et al. [22] reported that the larvicidal activity methanol extract 


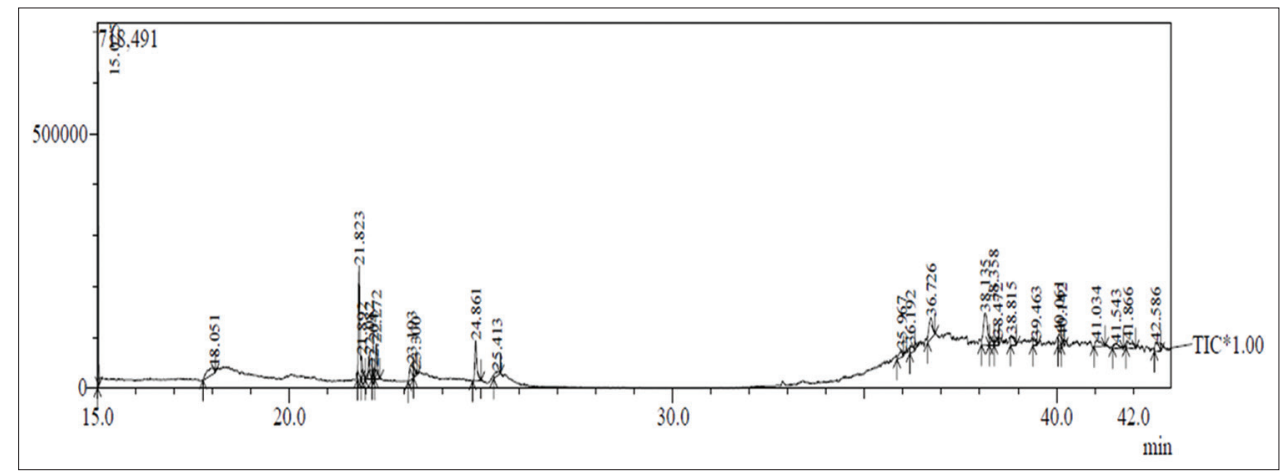

Fig. 1: Gas chromatography-mass spectrum of acetone extract of Solanum trilobatum leaves

Table 2: Phytochemical compounds identified in the acetone leaf extract of Solanum trilobatum leaves by GC-MS analysis

\begin{tabular}{|c|c|c|c|c|}
\hline S. No & RT & Area \% & Peak Height \% & Name of the compound \\
\hline 1 & 15.025 & 15.58 & 46.15 & Tungsten \\
\hline 2 & 18.051 & 4.65 & 0.73 & 1H-imidazole, 4,5-dimethyl-imidazole \\
\hline 3 & 21.823 & 12.42 & 14.43 & Cyclodecanol \\
\hline 4 & 21.783 & 2.90 & 2.99 & Disoamylene \\
\hline 5 & 22.082 & 2.76 & 2.96 & 3,7,11.15-Tetramethyl-2-hexadeen-1ol \\
\hline 6 & 22.204 & 1.34 & 1.45 & 1,2-Benzenedicarboxylic acid, Bis (2-methylpropyl) ester \\
\hline 7 & 22.272 & 4.30 & 4.44 & 1-Octadecyne \\
\hline 9 & 23.300 & 1.48 & 0.73 & Propennitrile, 3-ethoxy-2-(2-thienylm) \\
\hline 10 & 24.861 & 6.48 & 5.09 & 2-Tetradecycloxirane \\
\hline 11 & 25.413 & 1.58 & 0.61 & Bicyclo (3.2.1) octan-2-ol \\
\hline 12 & 35.967 & 2.01 & 0.89 & 2-(1-bromoethyl)-4,5-dimethyoxycarboxamid \\
\hline 13 & 36.192 & 2.04 & 1.06 & L-Alanine \\
\hline 14 & 36.726 & 6.07 & 2.68 & 3-Keto-isoteviol \\
\hline 15 & 38.135 & 10.25 & 4.07 & Beta-sitosterol \\
\hline 16 & 38.358 & 1.70 & 0.69 & 2-Chloro-5-iodo-benzoicacid pyridine-3-ylmethylene-hydrazide \\
\hline 19 & 39.463 & 1.36 & 0.78 & Permethrin-1, 3-phenoxybenzyl \\
\hline 20 & 40.061 & 2.38 & 1.51 & 1H-pyrazole-5-carboxamide \\
\hline 21 & 40.142 & 1.38 & 1.11 & 2-Cyclohexen-1-ol \\
\hline 22 & 41.034 & 2.63 & 0.81 & Benzene, 2-(tert-butyldimethylsilyl) oxy \\
\hline 23 & 41.543 & 1.99 & 0.66 & Hydrochlorothiazide N-butylbronate \\
\hline 24 & 41.866 & 2.83 & 0.84 & Silicic acid diethyl bis (trimethylsilyl) ester \\
\hline 25 & 42.586 & 3.48 & 1.22 & Isopropyl tris \\
\hline
\end{tabular}

GC-MS: Gas chromatography-mass spectrum

Table 3: Probit analysis for the data on larval mortality of acetone extract at $95 \%$ confidence limit

\begin{tabular}{|c|c|c|c|c|c|c|c|c|c|c|}
\hline \multirow[t]{3}{*}{ Hours } & \multicolumn{5}{|c|}{ Mean \% larval mortality } & \multirow[t]{3}{*}{$\mathbf{L C}_{50}$} & \multirow[t]{3}{*}{$\mathrm{LC}_{90}$} & \multirow[t]{3}{*}{ Regression equation } & \multirow[t]{3}{*}{$\mathbf{R}$ value } & \multirow[t]{3}{*}{ Chi-square value } \\
\hline & \multicolumn{5}{|c|}{ Concentration (ppm) } & & & & & \\
\hline & 100 & 200 & 300 & 400 & 500 & & & & & \\
\hline \multicolumn{11}{|c|}{ Culex quinquefasciatus } \\
\hline 24 & 25.33 & 37.33 & 54.67 & 70.67 & 86.67 & 265.69 & 558.27 & $Y=15.602 x+8.128$ & 0.99 & 0.74 \\
\hline 48 & 29.33 & 41.33 & 66.67 & 76 & 90.67 & 227.59 & 504.92 & $Y=15.735 x+13.59$ & 0.97 & 1.75 \\
\hline 72 & 33.33 & 45.33 & 62.67 & 80 & 94.67 & 212.42 & 479.09 & $Y=15.735 x+15.99$ & 0.99 & 2.89 \\
\hline \multicolumn{11}{|c|}{ Aedes aegypti } \\
\hline 24 & 17.33 & 32 & 52 & 66.67 & 81.33 & 301.09 & 582.34 & $Y=16.267 x+1.065$ & 0.996 & 0.261 \\
\hline 48 & 21.33 & 36 & 56 & 78.67 & 94.67 & 256.00 & 477.52 & $Y=18.935 x+0.529$ & 0.995 & 2.335 \\
\hline 72 & 29.33 & 45.33 & 64 & 90.67 & 97.33 & 209.75 & 419.40 & $Y=18.134 x+10.93$ & 0.977 & 4.632 \\
\hline 96 & 38.67 & 56 & 72 & 74.67 & 100 & 167.44 & 371.84 & $Y=15.467 x+20.531$ & 0.996 & 7.423 \\
\hline
\end{tabular}

Chi-square value significant at p<0.05 level. LC: Lethal concentration, LCL: Lower confident limit, UCL: Upper confidence limit

of $S$. trilobatum was found to be more susceptible against the larvae of A. aegypti, C. quinquefasciatus, and A. stephensi. Leaf extract of S. trilobatum also exhibited pupicidal and adult emergence properties [23,24]. The plant extract provides the bases to act as alternative to synthetic insecticide to control program of mosquito [25]. Finally, the study revealed that the plant origin chemicals from the $S$. trilobatum leaf extracts showed that insecticidal and medicinal values have higher efficiency in reducing mosquito menace due to their larvicidal toxicity. 


\section{CONCLUSION}

Results from the current study demonstrated that the acetone leaf extract of S. trilobatum has significantly higher larvicidal activity against selected human vector mosquitoes $C$. quinquefasciatus and $A$. aegypti. The phytochemicals present in $S$. trilobatum leaf extracts are effective mosquito vector control agents, and the plant extracts may be used for the further integrated pest management programs. In conclusion, the obtained results suggested that the effective plant crude extracts have the potential to be used as an ideal eco-friendly approach for the control of disease vectors.

\section{ACKNOWLEDGMENTS}

The authors are grateful to the management of PSG College of Arts and Science, Coimbatore, for their encouragement and providing facilities for this work. Thanks are also extended to NICD, Tamil Nadu, India, for providing the larvae for the current study and TNAU, Tamil Nadu, India, for plant identification.

\section{AUTHORS' CONTRIBUTIONS}

Author 1 has planned and conducted the experiment. The experiment was guided by Author 2 .

\section{CONFLICTS OF INTEREST}

The authors declare that there are no conflicts of interest regarding the publication of this article.

\section{REFERENCES}

1. WHO. Malaria fact Sheets No. 94. WHO Report; 2010.

2. Bagavan A, Rahuman A. Ealuation of larvicidal activity of medicinal palnt extracts against the mosquito vectors. Asian Pac J Trop Med 2010;4:29-34

3. Nilakshi G, Anil P, Kabita G, Bhattacharya DR, Nilanju PS, Chandrajit D, et al. An ethnobotanical survey of anti-malarial plants in some highly malaria affected districts of Assam. Int J Pharm Pharm Sci 2015;7:147-52.

4. Mohanraj RS, Devi KK, Dhankkodi B. Mosquitocidal activities of Spathodea campanulata methanolic leaf extracts against the dengue vector Aedes aegypti. Asian J Plant Sci Res 2013;3:138-149.

5. Sakthivadivel M, Gunasekaran P, Sivakaumar S, Samraj A, Arivoli S, Samuel T. Evaluation of Solanum trilobatum L (Solanaceae) aerial extracts for mosquito larvicidal activity against the filarial vector Culex quinquefasciatus Say (Diptera: Culicidae). J Entomol Zool Stud 2014;2:102-6

6. Pavela R. Larvicidal effects of various Euro-Asiatic plants against Culex quinquefasciatus say larvae (Diptera: Culicidae). Parasitol Res 2008;102:555-9.
7. Isman M. Botanical insecticides, deterrents and repellents in modern agriculture and an increasingly regulated world. Annu Rev Entomol 2006;55:45-66.

8. Govindhan S, Viswanathan S, Vijayasekaran V, Alagappan R. Further studies on the Clinical efficacy of Solanum trilobatum in bronchial asthma. Phytochem Res 2004;18:805-9.

9. Ramakrishna S, Ramana KV, Mihira V, Kumar PV. Evaluation of antiinflammator and alagestic activites of Solanum trilobatum Linn. Roots. Res J Pharm Biol Chem Sci 2011;2:701-5.

10. Kumar S, Wahab N, Warikoo R. Bioefficacy of Mentha piperita essential oil against dengue fever mosquito, Aedes aegypti L. Asian Pac J Trop Biomed 2011;1:90-3.

11. Jawhar M, Rabert GA Jeyaseelan M. Rapid proliferation of multiple shoots in Solanum trilobatum L. Plant Tissue Cult 2004;14:102-12.

12. Rajkumar S, Jebanesan A. Ovicidal activity of Solanum trilobatum Linn (Solanaceae) leaf extract against Culex tritaeniorhychus Giles (Diptera: Culicide). Int J Trop Sci 2004;24:340-2.

13. Amir M, Kumar S. Possible industrial application of genus Solanum in twenty first century-a review. J Sci India Res 2004;63:116-24.

14. Trease GE, Evans WC. Pharmacognosy. London: W.B. Scandars Company Ltd.; 1989. p. 269-300.

15. Abbott WS. A method of computing the effectiveness of an insecticide. J Econ Entomol 1925;18:265-7.

16. Balakrishnan P, Gani TM, Subrahmayam S, Shanmugam K. A perspective on bioactive compounds from Solanum trilobatum. J Chem Pharm Res 2015;7:507-12.

17. Doss A, Dhanabalan R. Preliminary phytochemical screening and antibacterial studies of leaf extract of Solanum trilobatum Linn. Ethnobot Leaflets 2008;12:638-42.

18. Sahu J, Rathi B, Koul S, Khosa RL Solanum trilobatum (Solanaceae) An overview. J Natl Remedies 2013;13:76-80.

19. Priya G, Chellaram C. Evaluation of antibacterial activity and phytochemical analysis of medicinal plant Solanum trilobatum. Int J Pharma Bio Sci 2014:5:354-9.

20. Akiyarma H, Kazuyasa F, Yamasaki D, Dono T, Iwatsuki K. Antibacterial action of several tannins against Stephylococcus aureus. J Antimicrob Chemother 2001;48:487-91.

21. Krishnaiah GM, Prashanth GK. Phytochemical studies and GC-Ms analysis of the leaf extracts of Melia azedarach Linn. Int J Adv Eng Technol Manag Appl Sci 2014;1:48-53.

22. Premalatha S, Elumalai A, Jeyasankar A. Mosquitocidal properties of Solanum trilobatum L. (Solanaceae) leaf extracts against three important human vector mosquitoes (Diptera. Culicidae). Asian Pac J Trop Biomed 2013;6:854-8.

23. Prabhakar K, Jabanesan A. Mosquitocidal effect of bitterguard leaf extracts. Bioresour Technol 2004;95:113-4.

24. Karunamoorthi K. Vector control: A cornerstone in the malaria elimination campaign. Clin Microbiol Infect 2011;17:1608-16.

25. Ashwini U, Taju G, Thirunavukkarasu P, Asha S. Pupal emergence inhibition activity of Acalypha indica leaf extract against dengue vector, Aedes albopictus mosquito. Int J Pharm Pharm Sci 2017;9:114-8. 